\title{
Rising Characteristics of a Single Measure of Gas Slug in Stagnant Liquid* (Effect of Pressure)
}

\author{
Masao NAKAZATOMI**, Hideo SHIMIZU**, \\ George MIYAKE** and Kotohiko SEKOGUCHI***
}

\begin{abstract}
The motion of a single measure of a gas slug in a vertical tube using a closed loop filled with stagnant liquid was studied to investigate the influence of the system pressure under a wide range from near atmospheric pressure to highly elevated pressure, e.g., $20 \mathrm{MPa}$. One purpose of this study was to investigate the influence of pressure on the rising velocity of the gas slug. The experimental equation was presented for rising velocity of the gas slug. The other purpose was to study the phenomenon of the liquid film around the gas slug as pressure increased. It was found that when liquid waves with liquid film around the gas slug appear, there are many bubbles with small diameters in the wake of the gas slug. The correlation of smooth liquid film length around the gas slug was presented.
\end{abstract}

Key Words : Multiphase Flow, Single Gas Slug, Bubble, Wave, Pipe Flow, Stagnant Liquid, Rising Velocity, High Pressure

\section{Introduction}

Many studies concerning the rising velocity of a single gas slug in stagnant liquid in a vertical tube have been reported experimental and theoretical analyses ${ }^{(1)}$. From these investigations, the rising veloity of a single gas slug is expressed as $C\left\{g \cdot D\left(\rho_{l}\right.\right.$ $\left.\left.-\rho_{g}\right) / \rho_{l}\right\}^{1 / 2}$ for a tube in the air-water system.

There are two main reasons for investigating this area of study in greater detail: (1) In order to promote the investigation of high-pressure air-water two-phase flow, the reason for the applicability of the above equation and constant $C$ in the equation to the region of high pressure must be determined. (2) From the observation of high-pressure air-water two -phase flow, the reason for the occurrence of waves on the liquid film around the single gas slug at relatively short lengths, and the reason for the increases in the content rate of the small gas bubbles in the liquid slug must be ascertained. Information which elucidates the above-mentioned phenomena will be obtained from

* Received 28th October, 1991. Paper No. 90-1155A

** Intelligent System Engineering, Ube Technical College, Tokiwadai, Ube-City 775, Japan

*** Department of Mechanical Engineering, Osaka University, 2-1 Yamadaoka, Suita-City, Osaka 565, Japan the detailed observation of the single gas slug.

In this report, observations concerning the rising velocity of the single gas slug, the liquid film behavior around the single gas slug, waves on the liquid film and the group of small gas bubbles in the wake of the single gas slug are discussed. Experiments were conducted under a wide range of pressures, from 0.3 to 20 MPa.

\section{Nomenclature}

$C$ : constant of Eqs. (1) and (2)

$D:$ tube inner diameter $\mathrm{mm}, \mathrm{m}$

$d$ : bubble length in tube axis direction $\mathrm{mm}, \mathrm{m}$

$g:$ acceleration of gravity $\mathrm{m} / \mathrm{s}^{2}$

$L_{B}$ : length of group of small bubbles $\mathrm{m}$

$L_{g t}$ : length of single gas slug $\mathrm{mm}, \mathrm{m}$

$L_{s F}$ : length from top of single gas slug to starting point of waves on liquid film around gas slug $\mathrm{mm}, \mathrm{m}$

$L_{S F}^{*}$ : dimensionless number of $L_{s F}$, Eq. (4)

$L_{t 0}$ : initial length of single gas slug $\mathrm{mm}, \mathrm{m}$

$n:$ number per unit length $1 / \mathrm{m}$

$P$ : pressure $\mathrm{MPa}$

$R e_{F \mathrm{crl}}$ : liquid film Reynold's number at starting point of waves

SBG : group of small gas bubbles in the wake of single gas slug 


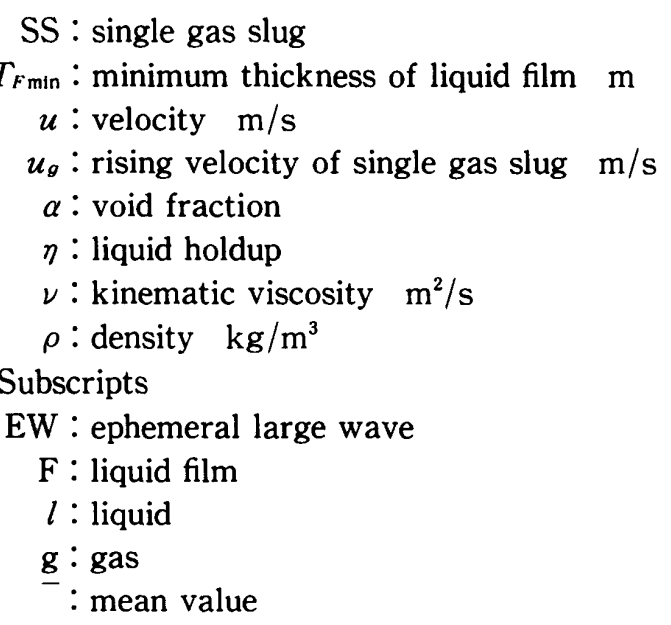

\section{Experimental Apparatus and Procedure}

The outline of the experimental apparatus is shown in Fig. 1. The inner diameter and the total length of the test section are $19.2 \mathrm{~mm}$ and $10.5 \mathrm{~m}$, respectively. The upper level of water in the separator is $0.5 \mathrm{~m}$ above the connection point between the separator and the test section. The inner diameter of the separator is $150 \mathrm{~mm}$. System pressure is maintained with compressed air from a high-pressure air tank being released by way of a valve (V1), and the maximum pressure possible is $20 \mathrm{MPa}$.

The procedure of the experimental method is as follows.

(1) The air for the single gas slug is introduced from valve (V 3) into the volume measuring area (VM) of the test section and is measured under the open condition of valve (V2).

(2) Valve (V2) is closed.

(3) When cock (C) on the top of VM is opened, the gas slug begins to rise in the test section.

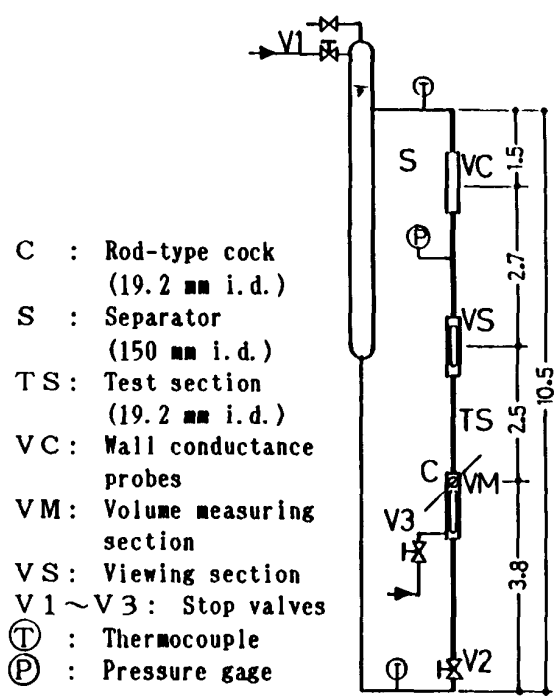

Fig. 1 Schematic diagram and size $(\mathrm{m})$ of the test section
(4) The gas slug rising in the test section is photographed at the viewing section (VS) and later, the liquid holdup of the gas slug is measured at the wall conductance probes $(\mathrm{VC})$.

(5) System pressure and liquid temperature are measured.

The experiment was performed with these procedures, and the experimental data were collected under the systematical change in the initial length of the gas slug and system pressure.

$\mathrm{VC}$ consists of 4 sets of ring-type sensors ${ }^{(2)}$; the distances between sensors $1 \sim 2,1 \sim 3$ and $1 \sim 4$ are 10.3, 71.4 and $81.7 \mathrm{~mm}$, respectively. The signals from VC were recorded by the data recorder. With the aid of a computer, the following values were calculated: the rising velocity and the length of the single gas slug, the liquid holdup around the gas slug, the starting point of waves and wave velocity on the liquid film around the gas slug, and the length and liquid holdup of the group of small bubbles in the wake of the single gas slug.

Experimental conditions were as follows: pressure $P=0.30,5.0,9.7,15.3$ and $19.9 \mathrm{MPa}$ (abbreviated in this paper as $0.3,5,10,15$ and $20 \mathrm{MPa}$ ) ; the initial length of the single gas slug, $L_{t 0}=0.0345 \sim 0.553 \mathrm{~m}$ (volume of air $(10 \sim 160) \times 10^{-6} \mathrm{~m}^{3}$ ); and temperature was $27.0 \sim 30.0^{\circ} \mathrm{C}$.

The ratio of the length from the rising start point cock $\mathrm{C}$ to the wall conductance probes $(\mathrm{VC})$ and the diameter of the test section is $L / D=270$. When the initial length of the single gas slug $L_{t 0}$ is especially large, it is uncertain whether or not the gas slug reaches a constant length by the time it reaches the measurement section.

\section{Results and Discussion}

\section{1 Photographic observation}

Photos 1 3 show the single gas slug (SS) that was photographed $2.5 \mathrm{~m}$ downstream from the rising start point (cock C in Fig. 1). Photographs (a) (e) of Photos 1 3 correspond to the pressure conditions $P=20,15,10,5$ and $0.3 \mathrm{MPa}$, respectively. However, in Photo 3 , the photo taken at $0.3 \mathrm{MPa}$ is excluded because the total length of the SS exceeds the length of the viewing section. In Photos $1 \sim 3$, the initial lengths of the SS are $L_{t 0}=0.0691,0.138$ and $0.242 \mathrm{~m}$, respectively.

When photos (a) $\sim(\mathrm{d})$ are magnified and compared with those where $P=0.3 \mathrm{MPa}$ and $P \geqq 5$ $\mathrm{MPa}$, the shapes of the tops of the SS are almost the same. From this result, it is assumed that the tops of the SS are hemispheric at $P=0.3 \sim 20 \mathrm{MPa}$, as well as at atmospheric pressure ${ }^{(3)-(5)}$. Thus, the discussion below is based on the theoretical analysis of Refs. ( 3 ) 


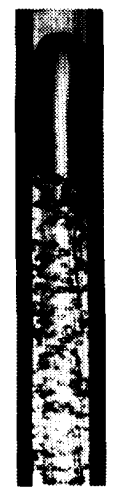

$P=20$

(a)

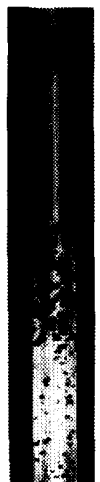

15

(b)

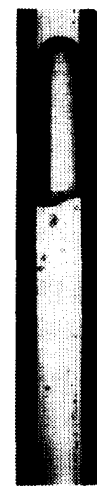

10

(c)

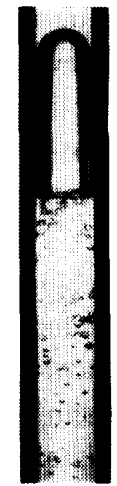

5

(d)

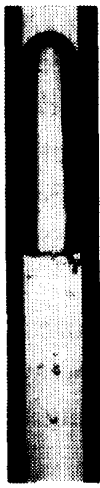

$0.3 \mathrm{MPa}$

(e )
Photo 1 Single gas slug $\left(L_{t 0}=0.069 \mathrm{~m}\right)$
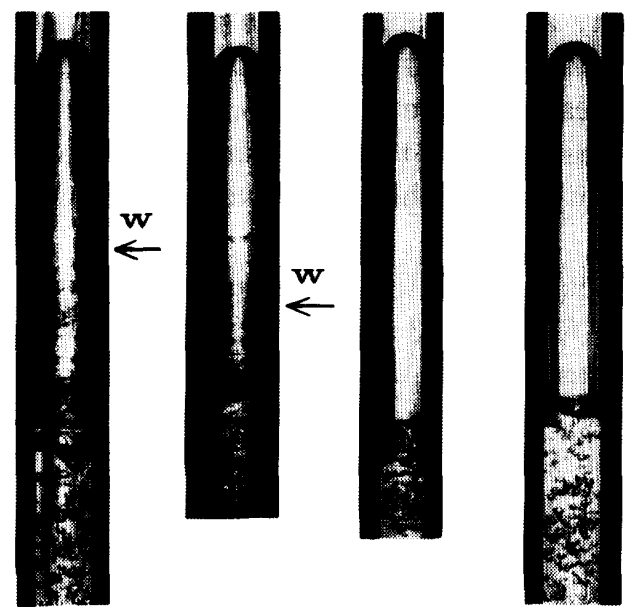

$\leftarrow W$ : Starting point of waves
$P=20$

(a)

\section{5}

(b)

\begin{abstract}
10
(c)
\end{abstract}

\begin{abstract}
5
\end{abstract}
(d)

$0.3 \mathrm{MPa}$

(e)
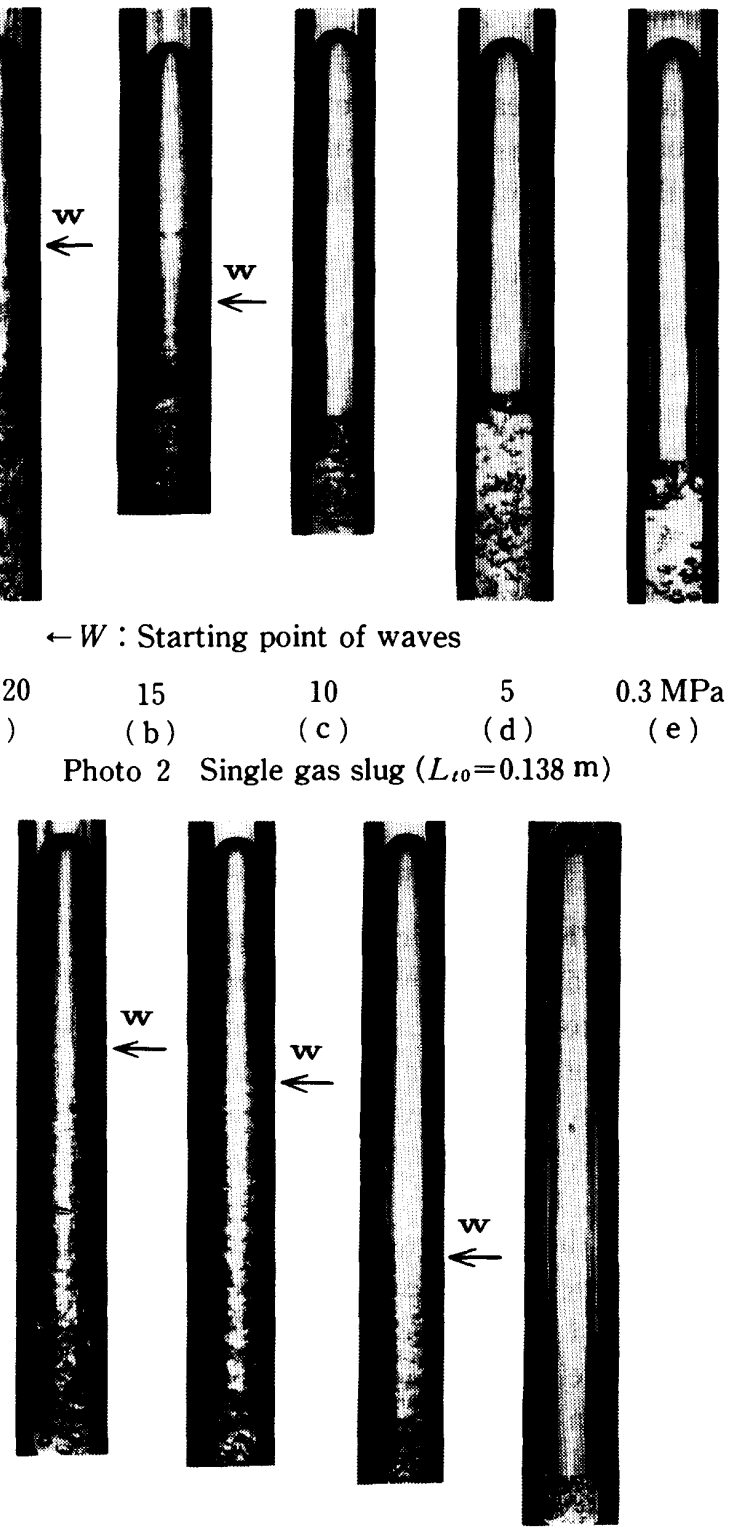

$\leftarrow W$ : Starting point of waves
$P=20$
15
(b)
10
$5 \mathrm{MPa}$
(d)
Photo 3 Single gas slug $\left(L_{t 0}=0.242 \mathrm{~m}\right)$

$\sim(5)$.

In Photo 1, all the liquid films around the SS are smooth. The two cases where $P=15$ and $20 \mathrm{MPa}$ (photos (a) and (b)), show many small gas bubbles in the liquid after the SS. However, only a few of the small gas bubbles are present in the three cases where $P \leqq 10 \mathrm{MPa}$ (photos (c), (d) and (e)) compared with (a) and (b).

In Photo 2 , in the cases where $P=15$ and $20 \mathrm{MPa}$, waves occur on the liquid film around the SS (symbols $\uparrow \mathrm{W}$ in the photos show the starting point of the waves). Also, many small gas bubbles are present in all cases, but they are less evident at lower pressure than at higher pressure.

In Photo 3, where the $L_{t 0}$ is larger, the waves on the liquid film around the SS occur at $P=10 \mathrm{MPa}$ (photo (c )). At a pressure of $5 \mathrm{MPa}$, the waves on the liquid film are absent, but when the $L_{t 0}$ becomes larger, the waves appear. At a pressure of $0.3 \mathrm{MPa}$, similar observations are made.

\section{2 Time-varying cross-sectional liquid holdup signals}

Figure 2 shows three sets of time-varying crosssectional liquid holdup signals $(\eta)$ measured when the SS is passing ( $\eta$-curve). Figure $2(1) \sim(3)$ show $L_{t 0}$ $=0.138,0.345$ and $0.553 \mathrm{~m}$, and Figs. $2(\mathrm{a}) \sim(\mathrm{e})$ show pressures of $0.3 \sim 20 \mathrm{MPa}$. Furthermore, Fig. 2 (1) and Photo 2 show the same experimental conditions. In Figs. ( 1$) \sim(3)$, the horizontal axes denote time ( $\mathrm{sec})$, and they are shifted to the right or to the left to match the top of the SS.

From Figs. $2(1) \sim(3)$, when the $L_{t 0}$ is larger, the $\eta$-curve consists of the preceding SS and the group of small gas bubbles (SGB). The small gas bubbles can be disregarded when $L_{t 0}$ is smaller and $P \leqq 10$ $\mathrm{MPa}$ (see Photos 1 ( c ) ( e )).

The length of the SS $\left(L_{g t}\right)$ and the SBG increase with an increase in $L_{t 0}$. In particular, where $P=5$ $\mathrm{MPa}$ and $L_{t 0}=0.553 \mathrm{~m}$ (see Fig. $2(3)$ ), the flow type is different from those of other pressures (see subsection 4.5 fo explanation).

As for the liquid film around the SS of Figs. 2 (2) and (3), waves are generated (symbols $\uparrow \mathrm{W}$ ) and liquid lumps (ephemeral large wave $(E W)^{(6),(7)}$ ) appear for $P \geqq 10$ or $15 \mathrm{MPa}$.

\section{3 Rising velocity of single gas slug}

In previous research into the air-water vertical tube, the rising velocities of the SS in stagnant liquid $\left(u_{g}\right)$ are shown as Eqs. $(1)^{(3) \sim(5)}$ and $(2)^{(8)}$ :

$$
\begin{aligned}
& u_{g}=C(g \cdot D)^{1 / 2} \\
& u_{g}=C\left\{g \cdot D\left(\rho_{l}-\rho_{g}\right) / \rho_{l}\right\}^{1 / 2}
\end{aligned}
$$

where constant $C$ assumes the values of $0.328^{(4)}$, $0.344^{(5)}$ and $0.35^{(3),(8)}$, as indicated by the researchers. Equation (2) includes the densities of both phases 
and is therefore used in this report. Constant $C$ in Eq. (2) is examined.

Figure 3 shows the relationship between $u_{\theta}$ and $L_{g t}$. From this figure, $u_{g}$ at $P \geqq 5 \mathrm{MPa}$ is constant so as to be unaffected by $L_{g t}$ at each pressure. When $L_{g t}$ becomes larger, waves occur on the liquid film around the SS, and the SBG in the wake of the SS becomes longer (see subsection 4.4 and Fig. 2). However, $u_{g}$ is not affected by these factors.

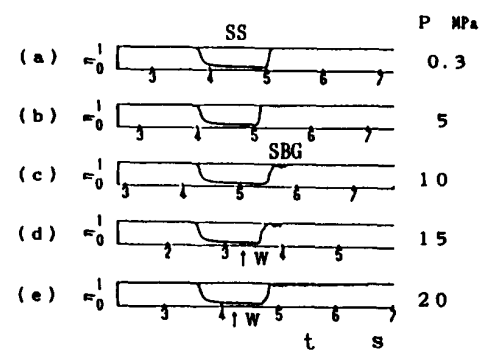

(1) Initial length of single gas slug $L_{10}=0.138$ a

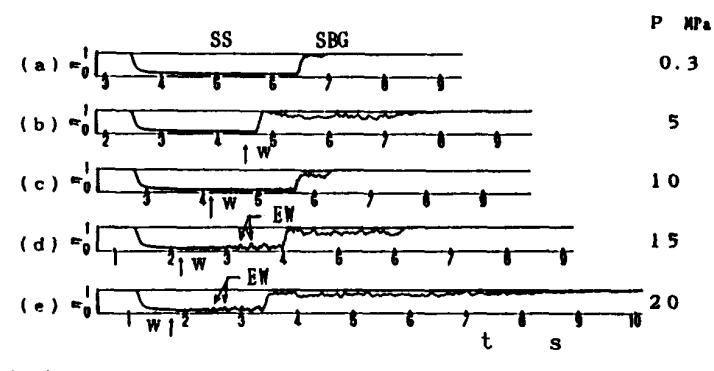

(2) Initial length of single gas slug $L_{10}=0.345$ ॥

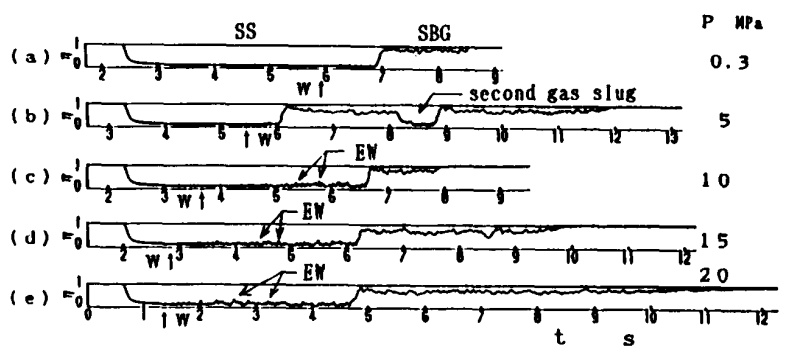

(3) Initial length of single gas slug $L_{t 0}=0.553$.

$\uparrow W:$ Starting point of waves, EW: Ephemeral large wave S S : Single gas slug, S B G : Group of saall gas bubbles

Fig. 2 Pressure effect on $\eta$-curve of single gas slug

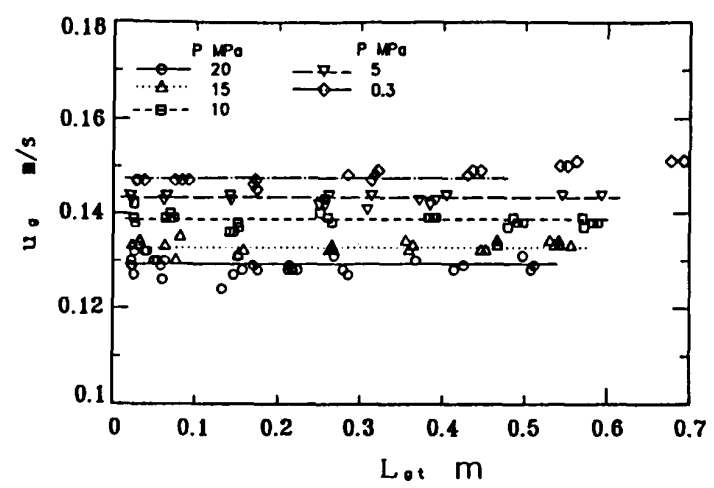

Fig. 3 Rising velocity of single gas slug $u_{\theta}$
The $u_{g}$ at $P=0.3 \mathrm{MPa}$ shows the tendency of the velocity of the SS to become larger in the region of $L_{g t} \geqq 0.55 \mathrm{~m}$. This tendency depends on a decrease in static pressure with the rising of the SS because the system pressure is low, as indicated by Nicklin et al. ${ }^{(9)}$ These data are excluded from the verification of Eq. (2).

Figure 4 shows the relationship between $u_{g}$ and $\left\{g \cdot D\left(\rho_{l}-\rho_{g}\right) / \rho_{l}\right\}^{1 / 2}$. The values of the main expres. sions already indicated are shown in Fig. 4. Harmathy ${ }^{(8)}$ used a value of 0.35 for the constant $C$, which is equivalent to the upper limit value for the experimental data. With these constraints, Eq. (2) can be used under high-pressure conditions.

However, the value of constant $C$ which shows greater agreement with the experimental data is 0.34 ; thus $u_{g}$ is expressed as follows

$$
u_{g}=0.34\left\{g \cdot D\left(\rho_{l}-\rho_{g}\right) / \rho_{l}\right\}^{1 / 2} \text {. }
$$

Equation ( 3 ) corresponds with most experimental data points within the $\pm 2.0 \%$ deviation range.

\subsection{Behavior of liquid film around the single gas slug}

When $L_{g t}$ becomes larger, waves occur on the liquid film around the SS. This phenomenon can be confirmed by the photo and the $\eta$-curve (see Photo 2 and Fig. 2). When waves occur, the content rate of small gas bubbles in the area in the wake of the SS increases, and it is found to relate closely to two factors (see subsection 4.2). In the case of $P=0.3$ $\mathrm{MPa}$, at $L_{g t} \geqq 0.55 \mathrm{~m}$, waves occur on the liquid film around the SS (but only toward the end of the liquid film).

When the pressure increases, the starting point of the waves on the liquid film shifts to the top of the SS. The length from the top of the SS to the starting point of the waves on the liquid film $\left(L_{S F}\right)$ is obtained using the photo and the $\eta$-curve (judged from the change in gradient of the $\eta$-curve). The total length of the viewing section is $0.3 \mathrm{~m}$; when $L_{g t}$ exceeds this, only

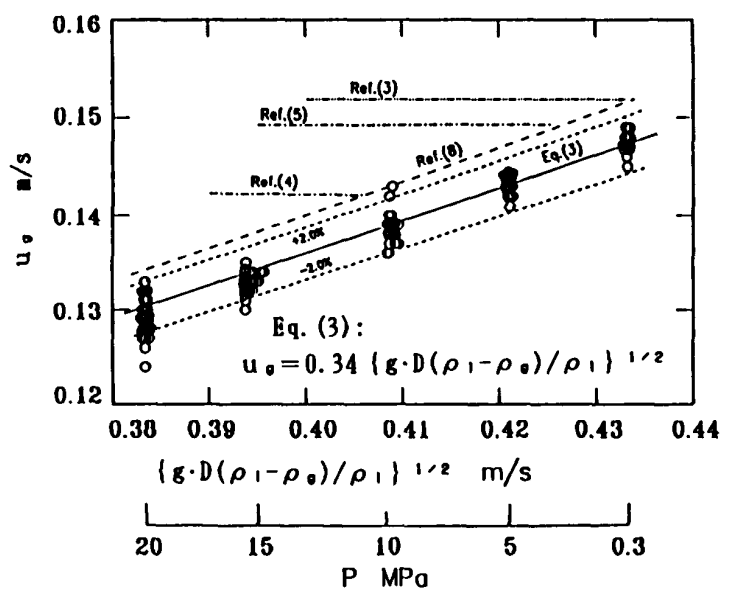

Fig. 4 Relationship between $u_{g}$ and $\left\{g \cdot D\left(\rho_{l}-\rho_{g}\right) / \rho_{l}\right\}^{1 / 2}$ 
the $\eta$-curve is used to measure.

Figure 5 shows the relationship between the pressure and $L_{g t}$, and the region with waves on the liquid film. SFR, WR and EWR in the figure show the region of smooth film, the region with waves and the region with ephemeral large waves, respectively. From the figure, at $P \geqq 5 \mathrm{MPa}$, the region with waves on the liquid film extends in the direction of short $L_{g t}$, and at $P \geqq 10 \mathrm{MPa}$, the region with ephemeral large waves is found.

Figure 6 shows the relationship between $L_{S F}$ and $L_{g t}$. The filled symbols indicate data points which show the smooth liquid film around the SS. $L_{S F}$ is not affected by $L_{g t}$ and almost indicates a constant value for each pressure. Also, the relationship between the dimensionless number $L_{S F}^{*}$ and $\left\{\left(\rho_{l}-\rho_{g}\right) / \rho_{l}\right\}$ is shown in Fig. 7. The solid line in the figure shows the following correlation.

$$
\begin{aligned}
& L_{S F}^{*}=L_{S F}\left(g / \nu_{l}^{2}\right)^{1 / 3} \\
& \quad=\exp \left[\left\{8.25\left(\rho_{l}-\rho_{g}\right) / \rho_{l}\right\}+1.0\right] .
\end{aligned}
$$

Most of the data points agree with Eq. ( 4 ) within a $\pm 6.0 \%$ deviation range ; only in the case of $P=0.3$ $\mathrm{MPa}$ are the values $20 \%$ larger.

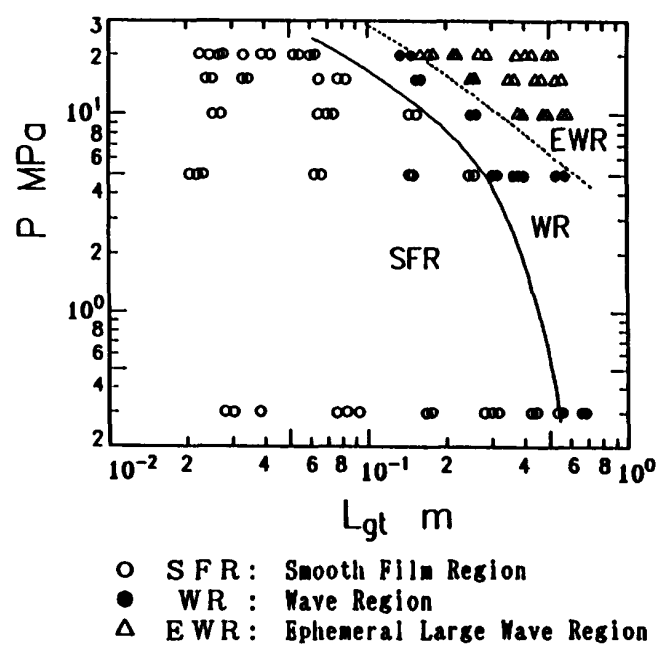

Fig. 5 Region with waves on liquid film around SS

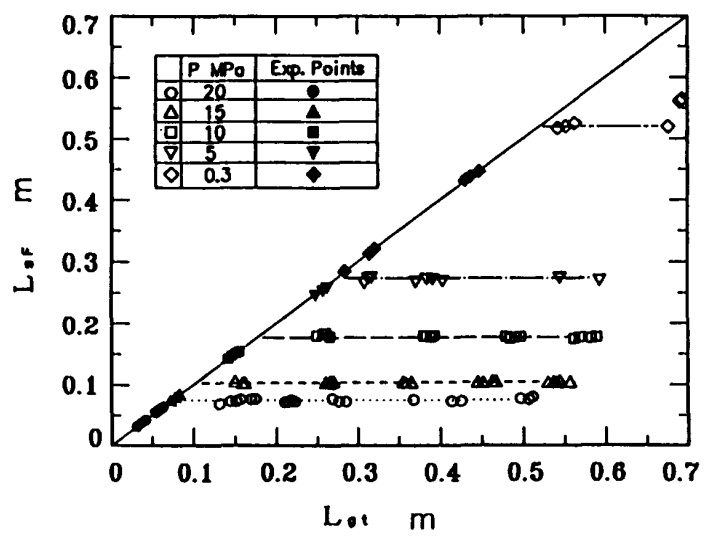

Fig. 6 Relationship between $L_{s F}$ and $L_{g t}$
The mean liquid film thickness at any point from the top of the SS becomes a minimum in the neighborhood of the starting point of the waves and thereafter shows a tendency to increase. In the region of $P \geqq 10$ $\mathrm{MPa}$ with ephemeral large waves (EW) (see Fig. 5), the mean liquid film thickness increases.

The reverse velocity of EW $\left(u_{E W}\right)$ is calculated from the $\eta$-curve of two sensors using the crosscorrelation method ${ }^{(10)}$. Figure 8 shows the relationship between the ratio $\left\{u_{E W} /\left(\bar{u}_{F}\right)_{E w}\right\}$ and $L_{g t}$, where $\left(\bar{u}_{F}\right)_{E W}$ is the mean reverse velocity of the liquid film with $\mathrm{EW}$. The value of the ratio varies considerably because the velocity $u_{E W}$ and the shape of EW have a variable nature; however a systematic effect under different pressure conditions appears. That is, with an increase in pressure, many of the values of $\left\{u_{E W} /\left(\bar{u}_{F}\right)_{E W}\right\}$ become less than unity, but the tendency remains with an increase in $L_{g t}$. The reverse velocity of the sine-type wave immediately behind the starting point of the waves is the same as the mean liquid film velocity at the same cross section $\left[\left\{u_{E W} /\left(\bar{u}_{F}\right)_{E W}\right\}=1\right]$.

Figure 9 shows the relationship between mininum film thickness around the SS $\left(\bar{t}_{F \min }\right)$ and $L_{g t}$. The parameter is pressure. In the small $L_{g t}$ region, the value of $\bar{t}_{F \min }$ decreases in a straight line with an

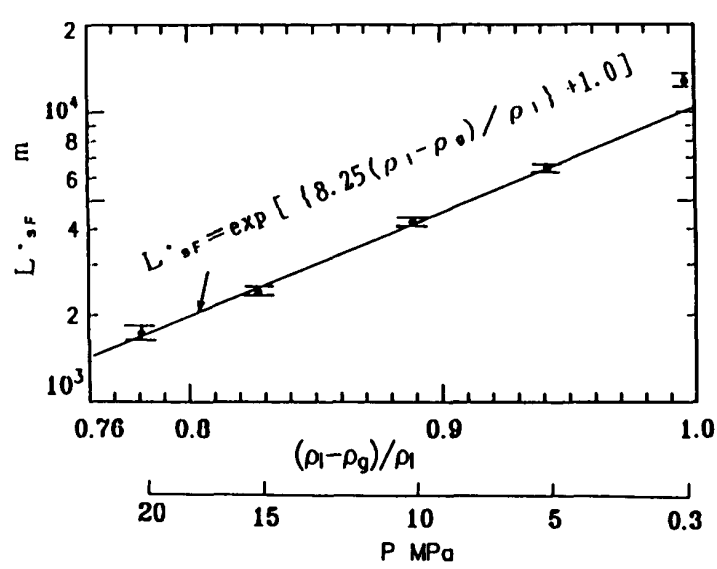

Fig. 7 Relationship between $L \xi_{F}^{*}$ and $\left\{\left(\rho_{l}-\rho_{g}\right) / \rho_{l}\right\}$

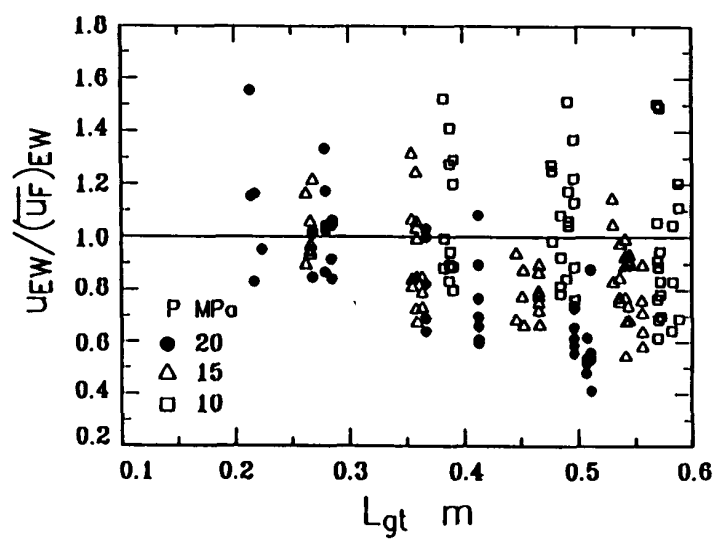

Fig. 8 Relationship between $\left\{u_{E W} /\left(\bar{u}_{F}\right)_{E W}\right\}$ and $L_{g t}$ 
increase in $L_{g t}$. Pressure has no effect. In the large $L_{g t}$ region, the value of $\bar{t}_{F \min }$ becomes constant for each pressure with an increase in $L_{g t}$. In the region affected by pressure, $\bar{t}_{F \min }$ becomes thinner with a decrease in pressure, but the values at $P=0.3$ and $5 \mathrm{MPa}$ are reversed.

Figure 10 shows the relationship between $R e_{F \mathrm{cr}}$ (Eq. $(5))$ and $\left(\rho_{l}-\rho_{g}\right) / \rho_{l} . R e_{F \text { crl }}$ is the liquid film Reynold's number in the region of constant $\bar{t}_{F \text { min }}$ for each pressure in Fig. 9.

$$
\operatorname{Re}_{\mathrm{F} \mathrm{cr}}=4 \bar{u}_{F} \cdot \bar{t}_{F \mathrm{~min}} / \nu_{l}
$$

Mean velocity $\bar{u}_{F}$ and $\bar{t}_{F \min }$ are calculated from the relation of continuity as follows.

$$
\begin{aligned}
& \bar{u}_{F}=(1.0-\bar{\eta}) \cdot u_{g} / \bar{\eta} \\
& \bar{t}_{F \min }=(D / 2) \cdot\left(1.0-\bar{\alpha}^{0.5}\right)
\end{aligned}
$$

$R_{F \mathrm{crl}}$ assumes a value of $2500 \sim 3000$ at $P=0.3$ $\sim 20 \mathrm{MPa}$. The solid line in Fig. 10 is denoted by the following equation.

$$
R e_{\mathrm{F} \mathrm{cl}}=745+2310\left(\rho_{l}-\rho_{g}\right) / \rho_{l}
$$

Equation $(6)$ is in agreement with experimental data points within the $\pm 2.0 \%$ deviation range.

\subsection{Group of small gas bubbles in the wake of the single gas slug}

The length of the group of small gas bubbles in

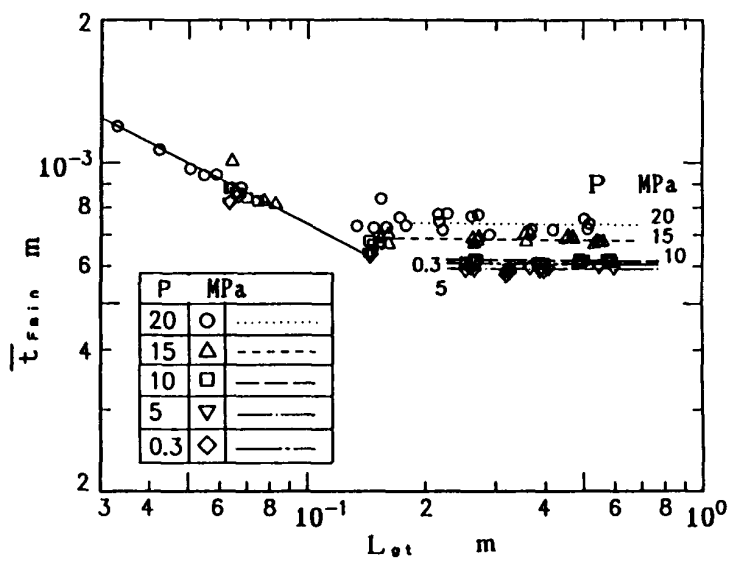

Fig. 9 Relationship between $\left(\bar{t}_{F \mathrm{~m} \text { n }}\right)$ and $L_{g t}$

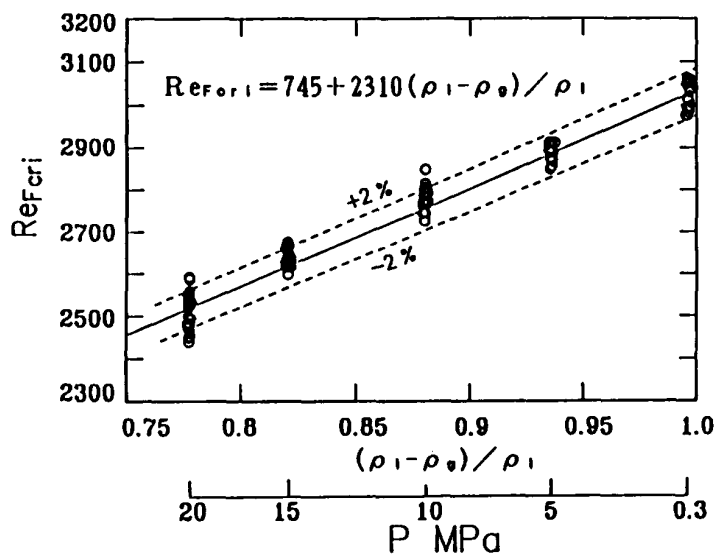

Fig. 10 Liquid film Reynold's number at starting point of waves around SS the wake of the SS (SBG) shows a different tendency, depending on pressure, as shown in Fig. 2. In the case of $P=5 \mathrm{MPa}$, at $L_{t 0} \geqq 0.449 \mathrm{~m}$, the length of SBG becomes longer and a second gas slug is formed by the combination of small gas bubbles. There is a $30 \%$ probability at $L_{t 0} \leqq 0.449 \mathrm{~m}$ and a $100 \%$ probability at $L_{t 0}=0.553 \mathrm{~m}$ that the second gas slug will form (see Fig. 2(3)). When $P=10 \mathrm{MPa}$, the length of SBG decreases compared with that at $P=5 \mathrm{MPa}$. In the case of $P \geqq 10 \mathrm{MPa}$, the length of SBG increases with an increase in pressure.

The mean void fraction profile of SBG along the tube axis differs according to pressure. However, the qualitative tendency of this group at all pressures is such that the cross sectional mean void fraction $\bar{\alpha}$ is maintained between $0.15 \sim 0.25$ along the tube axis and later decreases rapidly to zero.

Figure 11 shows the relationship between $L_{B} / L_{g t}$ and $L_{g t} . L_{B}$ is the length of SBG for $\bar{\alpha} \geqq 0.15$. There is a region where $L_{B} / L_{g t}$ is an almost constant value with an increase in $L_{g t}$ at all pressures. This region coincides with the region which has waves on the liquid film (see Fig. 5). The effect of pressure in Fig. 11 is such that $L_{B} / L_{g t}$ increases rapidly from 0.2 to 2.2 with an increase in pressure from 0.3 to $5 \mathrm{MPa}$. At 10 $\mathrm{MPa}, L_{B} / L_{g t}=0.3$. Later, $L_{B} / L_{g t}$ increases with an increase in pressure. Distinctive behavior of SBG can only be seen at $P=5 \mathrm{MPa}$.

Under the conditions of $P \geqq 15 \mathrm{MPa}$ and $L_{g t} \geqq 2 \cdot \mathrm{D}$, the liquid film around the SS is smooth, but the small gas bubbles are discharged (see Photos 1(a) and (b)). At $P \leqq 10 \mathrm{MPa}$, this phenomenon is not evident.

The sizes and size distribution of these SBG are measured and shown in Fig. 12. The size of bubble $d$ measured from the photos is the length running parallel to the tube axis. The figure shows the relationship between the number of bubbles per unit length of the test section $(n)$ and $d / D$. The distribution of $d$ is about $0.85 \sim 6.0 \mathrm{~mm}$ (the second slug of $P=5 \mathrm{MPa}$ is excluded). Where $P=0.3 \mathrm{MPa}$, the number of bubbles of $d / D \leqq 0.1$ is about one-half that of other pressures. At

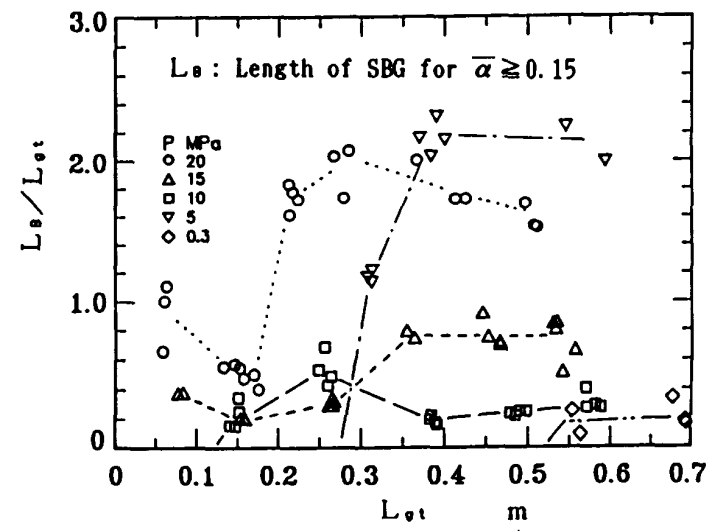

Fig. 11 Relationship between $L_{B} / L_{g t}$ and $L_{g t}$ 


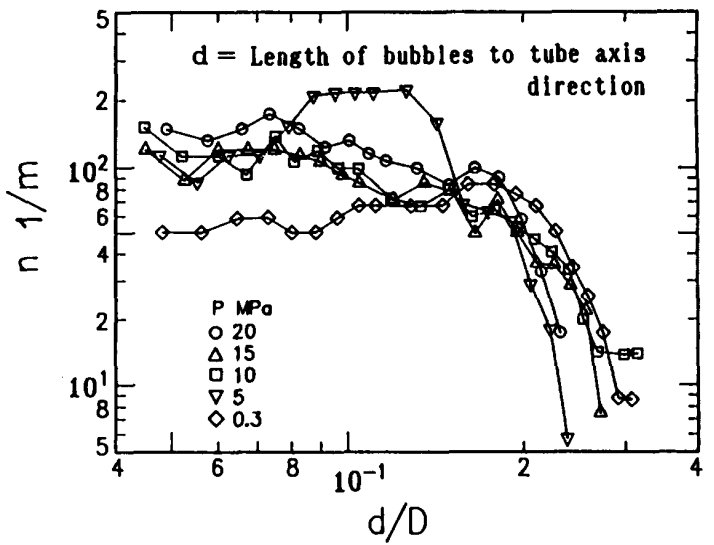

Fig. 12 Distribution of small gas bubbles following SS $\left(L_{t 0}=0.553 \mathrm{~m}\right)$

$P=5 \mathrm{MPa}$, the number of bubbles of $d / D=0.085 \sim 0.15$ is great compared with that at other pressures.

For $\bar{\alpha}=0.15 \sim 0.25$ of SBG, the distribution of $d$ under other experimental conditions is almost the same as that in Fig. 12. When the value of $\bar{\alpha}$ near the end of SBG becomes less than $0.15, \bar{\alpha}$ decreases rapidly to zero. In this region, the distribution of $d$ differs from that in Fig. 12, and relatively large bubbles with $d=3 \sim 6 \mathrm{~mm}$ are absent.

\section{Conclusions}

The flow characteristics of the single gas slug in stagnant liquid on a vertical tube were investigated experimentally with large variation in pressure $(P$ $=0.3 \sim 20 \mathrm{MPa}$ ). The results obtained are summarized as follows.

(1) Previous theoretical research concerning the rising velocity of the single gas slug was compared with experimental data. It is possible to apply Harmathy's correlation to high pressures up to 20 $\mathrm{MPa}$, but this gave a value slightly larger than our data. At the value of $C=0.34$, the value calculated agrees well with all the data at $P=0.3 \sim 20 \mathrm{MPa}$ with reliability within the $\pm 2.0 \%$ deviation range.

(2) The starting point of waves on the liquid film around the single gas slug was obtained experimentally and the correlation is shown.

(3) When the length of the single gas slug increased and waves occurred on the liquid film around the slug, the amount of discharge of small gas bubbles in the wake of the slug increased.

(4) The mean film thickness around the single gas slug was a minimum at the starting point of the waves, and later increased with the development of waves. At $P \geqq 10 \mathrm{MPa}$, the region where ephemeral large waves occurred was photographed and data were recorded.

( 5 ) The liquid film Reynold's number at the start. ing point of the waves was obtained experimentally and the correlation is shown.

(6) In the case where $P=5 \mathrm{MPa}$, there was a tendency for a second gas slug to be formed. In this region, the initial length of the gas slug was larger than $0.45 \mathrm{~m}$. Under other pressure conditions, the occurrence of a second gas slug was not in evidence.

\section{Acknowledgements}

The authors gratefully acknowledge that the main component of the experimental apparatus was constructed with the help of a special grant for equipment from the Ministry of Science, Education and Culture.

\section{References}

(1) Compiled by Jpn. Soc. Mech. Eng., Handbook of Gas-Liquid Two-Phase Flow Tchnology, (in Japanese), (1989), p. 232. Corona, Tokyo.

(2) Sekoguchi, K., Nakazatomi M., Takeishi, M., Shimizu, H., Mori, K. and Miyake, J., Velocity of Liquid Lumps in Vertical Upward Gas-Liquid Two-Phase Flow (Effect of Pressure), Trans. Jpn. Soc. Mech. Eng., (in Japanese), Vol. 57, No. 537, B (1991), p. 1823.

(3) Dumitrescu, D. T., Stromung an einer Luftblase im Senkrechten Rohr, Z. angew. Math. Mech., Vol. 23, No. 3 (1943), p. 139.

(4) Davies, R. M. and Taylor, G. I., The Mechanism of Large Bubble Rising through Extended Liquids and through Liquids in Tubes, Proc. Royal Soc. (London), Vol. A200 (1950), p. 375.

(5) Collins, R., The Effect of a Containing Cylindrical Boundary on the Velocity of a Large Gas Bubble in a Liquid, J. Fluid Mech., Vol. 28, No. 1 (1967), p. 97.

(6) Takeishi, M., Sekoguchi, K., Shimizu, H. and Nakazatomi, M., Velocity of Liquid Lumps in Vertical Upward Gas-Liquid Two-Phase Flow, Trans. Jpn. Soc. Mech. Eng., (in Japanese), Vol. 53, No. 493, B (1987), p. 2800.

( 7 ) Sekoguchi, K., Takeishi, M., Cognet, G., Ishimatu, T. and Yahiro, K., Patterns of Liquid Lump Behaviors in Vertical Upward Gas-Liquid TwoPhase Flow, Trans. Jap. Soc. Mech. Eng., (in Japanese), Vol. 53, No. 493, B (1987), p. 2807.

(8) Harmathy, T.Z., Velocity of Large Drops and Bubbles in Media of Infinite or Restricted Extent, AIChE. J., Vol. 6, No. 2 (1960), p. 281.

(9) Nicklin, D. J., Wilke, J.O. and Davidson, J. F., Two-Phase Flow in Vertical Tubes, Trans. Inst. Chem. Engr., Vol. 40, No. 1 (1962), p. 61.

(10) Sekoguchi, K., Morikawa, K., Takahashi, K., Takeishi, M. and Fukano, T., Flow Mechanism in Transition Region to Froth and Annular Flow (1st Report; Liquid Lumps), Trans. Jpn. Soc. Mech. Eng., (in Japanese), Vol. 49, No. 437, B (1983), p. 91. 